\title{
Detection of Anthropogenic Climate Change: A Modeling Study
}

P. B. Duffy

P. G. Eltgroth

February 17, 1999

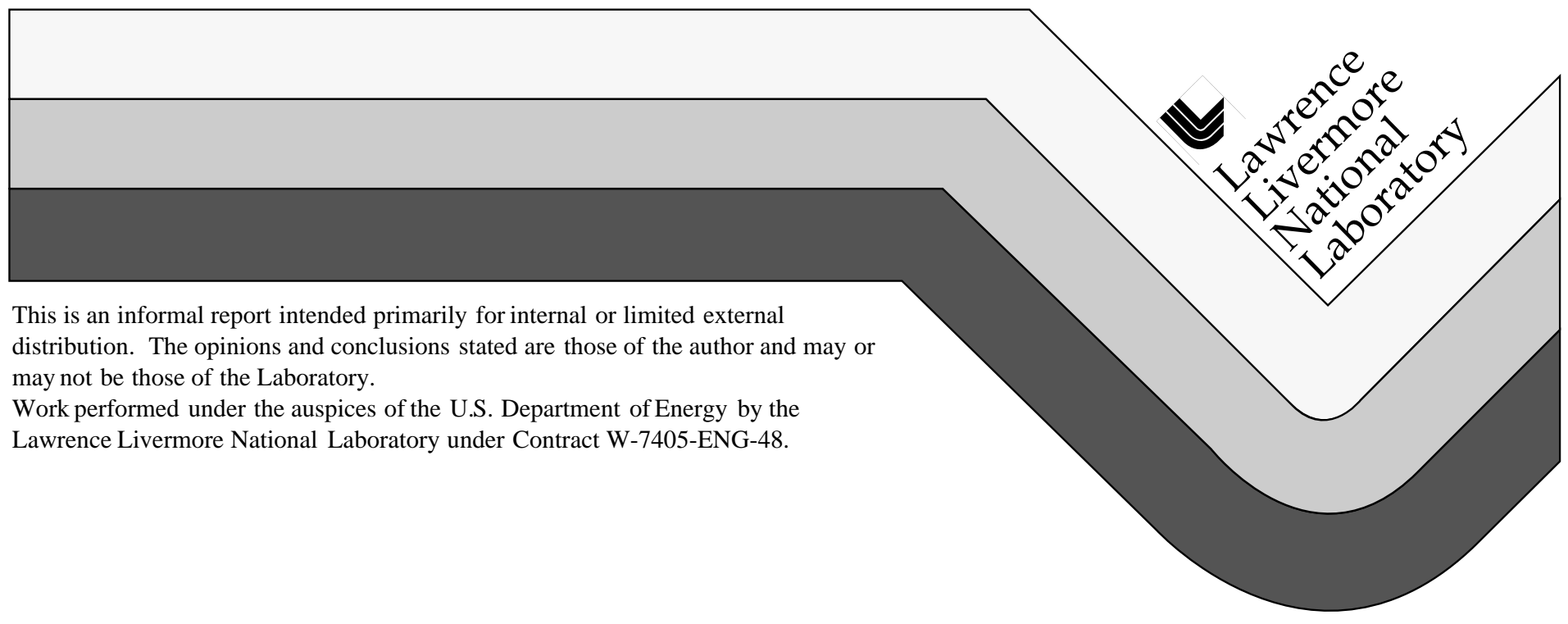




\section{DISCLAIMER}

This document was prepared as an account of work sponsored by an agency of the United States Government. Neither the United States Government nor the University of California nor any of their employees, makes any warranty, express or implied, or assumes any legal liability or responsibility for the accuracy, completeness, or usefulness of any information, apparatus, product, or process disclosed, or represents that its use would not infringe privately owned rights. Reference herein to any specific commercial product, process, or service by trade name, trademark, manufacturer, or otherwise, does not necessarily constitute or imply its endorsement, recommendation, or favoring by the United States Government or the University of California. The views and opinions of authors expressed herein do not necessarily state or reflect those of the United States Government or the University of California, and shall not be used for advertising or product endorsement purposes.

This report has been reproduced directly from the best available copy.

Available to DOE and DOE contractors from the Office of Scientific and Technical Information P.O. Box 62, Oak Ridge, TN 37831

Prices available from (423) 576-8401

Available to the public from the National Technical Information Service

U.S. Department of Commerce 5285 Port Royal Rd. Springfield, VA 22161 


\title{
Detection of Anthropogenic Climate Change: A Modeling Study
}

\author{
P. B. Duffy, Atmospheric Science Division \\ P.G. Eltgroth, Center for Applied Scientific Computing \\ et al. \\ 98-ERD-007
}

\section{Introduction}

This project involved two related areas of research: (1) simulating natural climate variability using a global climate model, and (2) using the computer resources of the Accelerated Strategic Computing Initiative (ASCI) Blue computer for specific problems in atmospheric science and climate. Although originally scheduled to last two years, this ER project ended after one year; the work is begin continued under a larger (Strategic Initiative) project which started in FY99.

\section{Natural Climate Variability}

Background: Understanding natural climate variability is central to knowing whether or not observed climatic changes result from human activities. Of particular importance for this purpose is understanding natural climate variability on multi-decadal and century time scales. Progress in understanding natural climate variability on these time scales has been slow, because sufficient observational data do not exist, and because relevant model simulations are so computationally demanding that they are nearly impossible to complete. Our goals here were to evaluate (1) whether simulated natural climatic variability is sensitive to details of the model used to make the simulation and (2) whether models can be improved so that the simulated variability agrees with observed variability.

Technical Approach: To adequately simulate climate variability on multidecadal and century time scales, simulations of about 1,000 simulated years duration are needed. As discussed above, such simulations are so demanding computationally that only a few have ever been performed. In order to be able to perform a large number of these simulations, we used a climate model which includes a highly simplified representation of the atmosphere. The rationale for choosing this type of model is that multi-decadal and century time scale climate variability is thought to originate predominately in the ocean and sea ice; at the same time, in fully-detailed climate models, the bulk of the computer time is spent simulating the atmosphere. Thus, for this problem, a model with a detailed representation of the ocean and sea ice and a simplified representation of the atmosphere is a good choice. We adopted the atmosphere-ocean-sea ice model of Fanning and Weaver (1996), which consists of an energy/moisture balance model of the atmosphere, a dynamic/thermodynamic sea ice model, and the GFDL MOM2 ocean general circulation model (Pacanowski, 1995). The original version of this model runs only on single-processor computers; to obtain improved throughput, we decided to create a version capable of running on massively parallel computers.

Results: In FY98, we focused mainly on improving the Fanning and Weaver model. First, we successfully parallelized two major components (the atmospheric and sea-ice modules) of the model. In addition, we made an improvement to the 
model's physics (improved coupling between the oceanic and sea-ice modules; Duffy et al. 1999) which allowed the model to obtain a significantly improved simulation of the present-day climate. Finally, we performed several 1,000-year simulations of natural climate variability using the improved coupled ocean-atmosphere-sea-ice model. Preliminary analysis of the results shows reasonable levels of simulated variability and interesting sensitivity of the variability to model parameters and configuration.

\section{Using ASCI Computational Resources for Climate Research}

Background: Lack of computer resources is an important, perhaps increasingly important, factor limiting progress in modeling of climate and other aspects of atmospheric science. The existence of extraordinary computational capabilities at DOE Labs, and the close association of global warming with energy usage (specifically burning of fossil fuels) make it highly appropriate for DOE to be heavily involved in large-scale simulations of climate and other atmospheric processed. In particular, applying LLNL's best computational resources to simulations in atmospheric science and climate would give LLNL extraordinary capabilities in these areas, and would give us the ability to perform high-impact climate-change simulations. The goal of this task, therefore, was to develop the ability to apply LLNL's ASCI-related computational resources to a variety of problems in atmospheric and climatic simulation.

Results: We worked on adapting several atmosphere and ocean models to execute on LLNL's ASCI Blue Pacific computer. These models are to be used for simulating global and regional climate, and the transport and fate of hazardous materials in the atmosphere. One major task was to start parallelization of the U.S. Navy's Coupled Oceanic-Atmospheric Mesoscale Prediction System (COAMPS); this is a regional atmospheric model to be used for simulating both regional climate and "transport and fate" of hazardous materials in the atmosphere. In FY98, we reached a major milestone in this parallelization project: the successful testing of the model's dynamics using multiple processors.

Related to the COAMPS parallelization task was a task whose goal was to assess the degree to which the results of "transport and fate" simulations are sensitive to meteorological initial conditions. The motivation for this task was the concern that lack of knowledge of meteorological conditions at the start of the simulation might introduce major uncertainties into the results of calculations of the transport and fate of hazardous materials in the atmosphere. To address this concern, we performed ensembles of transport and fate simulations, in which all the simulations were identical except for using slightly different meteorological conditions at the start of the simulations. We found that the predicted transport and fate of hazardous materials on the whole exhibit low sensitivity to meteorological initial conditions. That is, most of the uncertainty in the final results is due to factors other than lack of knowledge of meteorological initial conditions.

Another major task was to port two global climatic models-the National Center for Atmospheric Research (NCAR)] CCM3 atmosphere general circulation model and the POP ocean general circulation model-to multi-processor machines 
at LLNL, including ASCI Blue Pacific. These models, together with the CICE sea ice model, will form the basis of the "next generation Climate System Model" being jointly developed by NCAR, LLNL, and LANL. The porting of CCM3 and POP to ASCI Blue Pacific and the LLNL DEC systems is complete; however, for a variety of reasons, the parallel efficiency of these models when run with a large number of ASCI Blue TR processors was relatively poor. In the case of CCM3, factors limiting parallel efficiency include: the use of global interprocessor communication in the model dynamics; an inefficient approach to assigning model grid cells to processors ("1-dimensional domain decomposition"), and Blue system software which resulted in relatively slow message-passing between processors. A planned system software upgrade should remedy this last problem. After this is in place, we will re-evaluate the performance of CCM3 on Blue Pacific and decide what further changes (if any) are needed to improve the performance.

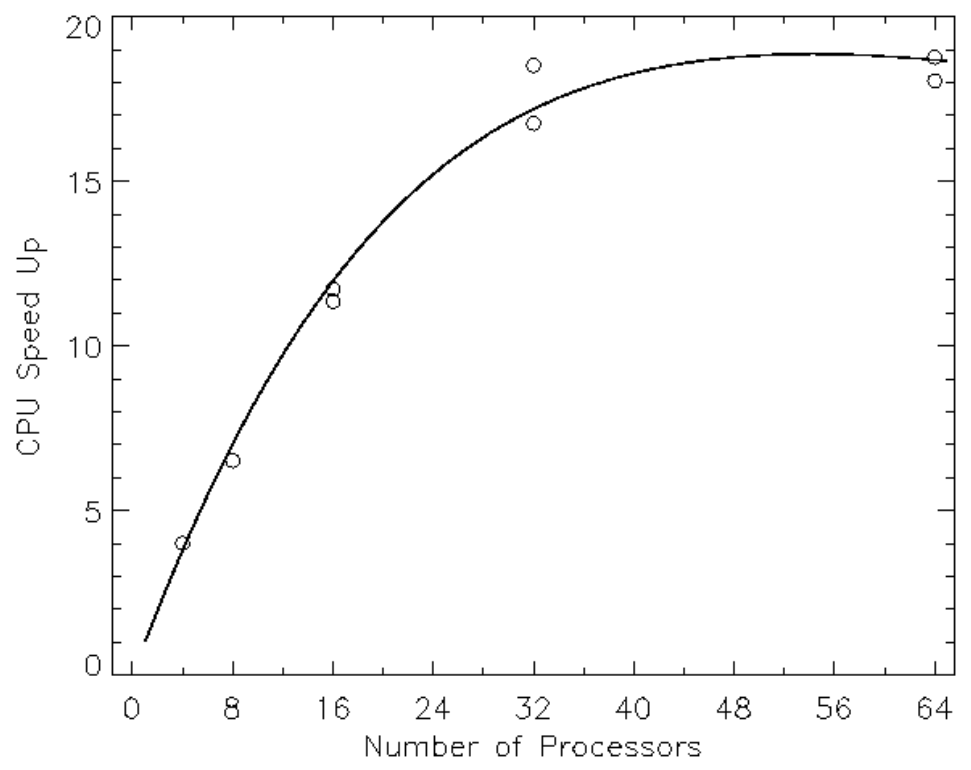




\section{Model - CCM3}

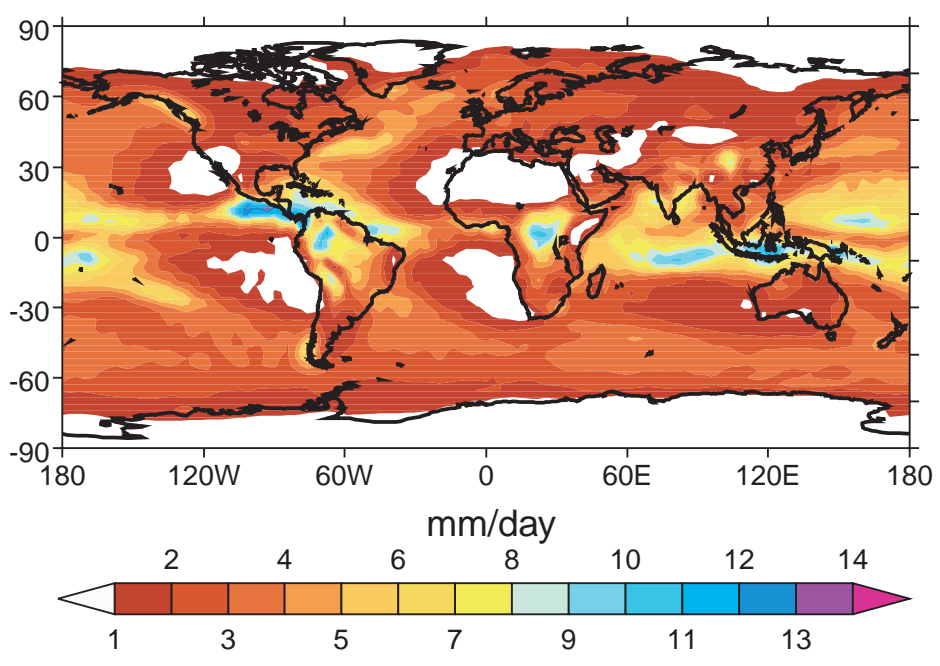

Observation

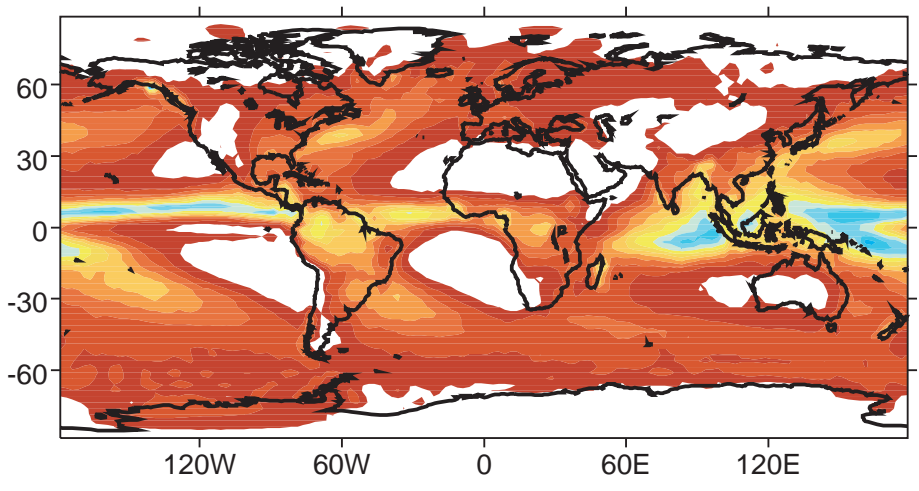

Figure 2: A result from a simulation performed with the CCM3 atmosphere/slab ocean model on an LLNL multi-processor computer. The top panel shows annual mean precipitation as simulated by the model. For comparison, the bottom panel shows precipitation from "reanalysis" - a model simulation forced to agree with available observations-performed by the National Center for Environmental Prediction (NCEP).

\section{Conclusions}

This project had a science component and a model development component. In the science component, we started performing a series of $1,000+$ year climate model simulations aimed at improving our understanding of natural climate variability on multi-decadal and century time scales. Improving this understanding is essential to determining how much, if any, of observed climate change is due to human activities. In the model-development component of the project, we adapted a regional ocean-atmosphere model, a global atmosphere model, and a global ocean model for use on the LLNL ASCI Blue Pacific TR computer. Applying this class of computer to simulations of the atmosphere and climate should lead to better understanding of climate change and related issues. This project was terminated after one year (instead of the originally-intended two) to allow a larger Strategic 
initiative (SI) project with similar goals to be proposed. The work started under this project is now being continued under that SI.

\section{References}

Duffy , P. B., M. Eby and A.J. Weaver, Effects of Sinking of Salt Rejected During Formation of Sea Ice on Results of a Global Ocean-Atmosphere-Sea Ice Climate Model, submitted to Geophys. Res. Lett., 1999.

Fanning, A.F. and A.J. Weaver, An atmospheric energy-moisture balance model: climatology, interpentadal climate change, and coupling to an ocean general circulation model, J. Geophys. Res. 101, 15,111-15,128, 1996.

Pacanowski, R.C. "MOM 2 Documentation, User's Guide and Reference Manual”, GFDL Ocean Technical Report \#3, 1995.

\section{Publications}

Duffy, P. K. Caldeira, "Sensitivity of Simulated Salinities in a Three-dimensional Ocean General Circulation Model to Vertical Mixing of Destabilizing Surface Fluxes," Climate Dynamics, in press, UCRL-JC-129901.

Duffy, P. B., M. Eby and A.J. Weaver, Effects of Sinking of Salt Rejected During Formation of Sea Ice on Results of a Global Ocean-Atmosphere-Sea Ice Climate Model, submitted to Geophys. Res. Lett., 1999.

Govindasamy, B., M. Wehner, C. R. Mechoso, P. B. Duffy, "The Influence of a Land The Influence of a Land Surface Scheme on Simulated Climate by LLNL/UCLA AGCM," Global and Planetary Change, 20, 67-86, 1999, UCRL-JC-130941.

Caldeira, K., G. Rau, P. Duffy, "Predicted oceanic degassing of radiocarbon and increase in atmospheric radiocarbon content," Geophysical Research Letters," 25, 3811-3814, 1998, UCRL-JC-127868.

Duffy, P. and K. Caldeira, "Sensitivity of simulated CFC-11 distributions in a global ocean model to the treatment of salt rejected during sea-ice formation," Geophysical Research Letters, 25, 1003, UCRL-JC-127709. 